Fecha de recepción: septiembre 2013

Fecha de aceptación: abril 2014

Versión final: septiembre 2015

\section{Una apertura de Pina. \\ Algunas reflexiones en torno al documental de Wim Wenders}

Virginia E. Zuleta *

\begin{abstract}
Resumen: Este artículo se propone una lectura del largometraje Pina (2011) de Wim Wenders. Documental que trata sobre la historia de la bailarina Pina Bausch, más precisamente, la historia de Pina en tanto directora y coreógrafa de Tanztheater Wuppertal. Filmado en escenario urbanos y naturales de la ciudad alemana -Wuppertal, hogar de la compañía- y con la ayuda de la tecnología 3D, el film se compone de fragmentos de obras, memorias-bailadas por los integrantes de la compañía e imágenes-archivo.

Como punto de partida tematizaremos la noción de ensayo-fílmico y su vínculo con el documental biográfico. Describiremos algunos aspectos del largometraje que a nuestro entender podrían resonar con este no-género llamado ensayismo-fílmico. Trabajaremos con las imágenes del film no como "representaciones" de una realidad, sino como productoras; las imágenes no sólo producen el mundo, sino que nos producen. En este sentido, el "nos" que acompaña el verbo "producir" nos interpela, en tanto subjetividad. Y nos preguntamos ¿qué sería de Pina sin estas imágenes que posibilitan pensarla? ¿Es posible pensarla como algo independiente de la producción de imágenes? Creemos que abrir una pregunta acerca de lo biográfico implica interrogarse sobre la subjetividad y sus modos de producción. A partir de estos problemas, tematizaremos sobre el espacio del teatro -su adentro y su afuera- para poder pensar un espacio "otro" de la danza, el cuerpo del bailarín -en tanto actor-productor.
\end{abstract}

Palabras clave: Pina - cine - ensayo fílmico - Wenders.

[Resúmenes en inglés y portugués en la página 49]

${ }^{(*)}$ Licenciada en Filosofía (UNSJ). Desde el 2011 se desempeña como Becaria de Postgrado de CONICET. Alumna del Doctorado en Ciencias Sociales (UBA). Actualmente está finalizando sus estudios en la Maestría en Comunicación y Cultura (UBA), en la que orienta su investigación al pensamiento de Gilles Deleuze.

\title{
Presentación
}

Lo que impulsa este trabajo es abrir una pregunta acerca del género biográfico en el cine, más específicamente en el film Pina (2011) de Wim Wenders. Un documental titulado con un nombre propio podría aspirar a "representar" esa vida. Sin embargo, consideramos que el trabajo que realiza Wenders no es una duplicación del mundo (en este caso de esa vida particular) o su ilustración a partir de las imágenes. La "imágenes” son productoras, 
como señala Ulm (2011, p. 151) "[1]as imágenes antes de duplicar lo visible del mundo, lo producen tanto como nos producen en ese horizonte abierto de y por lo visible". Este trabajo no se embarcará en indagar qué "representan" las imágenes que filma, selecciona y monta Wenders, ya que esta vana búsqueda sólo podría servir para afirmar que detrás de una imagen no hay nada excepto otra imagen. Enunciado que podríamos acompañar con unas palabras de Friedrich Nietzsche: "[t]oda filosofía escondel también una filosofía; toda opinión es también un escondite, toda palabra, también una máscara” (2007, p. 249). Pero, ¿qué presupuestos trae decir todo esto? En un primer deshilar de esta maraña teórica, podemos sostener que ya no es posible pensar en términos de "representación" en tanto copia de un "real", o dicho platónicamente de una "idea". Y, como sosteníamos anteriormente, no hay razón para bucear en una imagen buscando qué representa, ni sumergirnos en aguas profundas para intentar construir un único sentido. Las imágenes, ya lo decíamos con Ulm, no sólo producen el mundo, sino que nos producen. En este sentido, el "nos" que acompaña el verbo "producir" nos interpela, en tanto subjetividad. Y nos preguntamos, ¿qué sería de Pina sin estas imágenes que posibilitan pensarla?, ¿es posible pensarla como algo independiente de la producción de imágenes? Creemos que abrir una pregunta acerca de lo biográfico en este film implica interrogarse sobre la subjetividad y sus modos de producción.

\section{Pina en tanto ensayo-fílmico: algunas notas}

No podemos evitar la deriva de nuestro tema de interés al terreno del "cine-ensayo", si consideramos que éste, desde ciertos planteos, es visto como una culminación del documental, o en posturas más extremas como el rebasamiento de aquel paradigma. No obstante ello, no creemos que sea fructífero abrir aquí un debate acerca de qué puede o no considerarse "film-ensayo", "cine-ensayo", ya que, podríamos perdernos y así estar condenados a naufragar en el mar de los debates teóricos que trae consigo un concepto tan "fugitivo" (Cfr. Weirnrichter 2007). El "cine-ensayo" sigue siendo una noción que convoca materiales de los más disímiles. Desde una visión subjetiva, pone en cuestión -entre otras cosas- la posibilidad de "representación" de la realidad. Librándose de ataduras conceptuales, resistiendo a todo tipo de clausura, de sistematización y a ser catalogado como un género, es descripto como la superación del documental, etnografía experimental, el horizonte al que había tendido el cine factual, etc. Algunos han intentado construir un cierto linaje desde esta noción -tomándola en un sentido restringido-, corriendo el riesgo de desplazar todos aquellos films que no cumplen con ciertos modos y formas. En el punto extremo de esta postura, otros intentan incluir dentro de esta noción todo film que se construya de manera autoreflexiva.

Siguiendo a Weinrichter en "Un concepto fugitivo. Notas sobre el film-ensayo", podemos sostener que "la noción de film-ensayo sólo podía apreciarse en un contexto de crisis del cine convencional” (2007, p. 18). Así el ensayo señala una madurez cinematográfica, al mismo tiempo que puede verse desde la lupa de la forma "post-" (postmodernidad, postestructuralismo, postdocumental, posvérité). En ese artículo se propone un rastreo de la 
noción de "film-ensayo", sus avatares y derivas. Tomando distancia de denominaciones demasiadas restrictivas -como aquellas que intentan ver en el "cine-ensayo" sólo un tipo de documental personal, ignorando ciertos aportes del campo experimental y artístico, u otras que simplemente lo etiquetan como un cine de no ficción-. Insistiendo en la imposibilidad de describir el "cine-ensayo" como un modelo formal. En una lectura trasversal del artículo uno podría convocar la imagen de "cierta enciclopedia china" borgeana que da comienzo al texto: Las palabras y las cosas (Cfr. Foucault, 1968). Invitándonos a pensar acerca de los límites que suscitan las definiciones, los conceptos fijos, las taxonomías. Habiendo visto la imposibilidad de definir un no-género como el "cine-ensayo" y no apelando a comodidades, sólo nos resta buscar las resonancias que suscita esta noción. Compartimos con Weinrichter que es posible calificar ciertos films o segmentos de algunos, con el adjetivo ensayístico, apelando a un modo de escritura que no se ajusta a los moldes de los géneros. A partir de este breve recorrido y problematización de la noción de ensayofílmico, podemos describir el largometraje Pina (2011) como un film que desborda lo que clásicamente se ha entendido por documental (biográfico) y hace resonancia en esta noción "fugitiva". Este documental -lo llamaremos así apelando a una economía discursiva- desde nuestra lectura tiene como apuesta estética una (re)escritura de la vida de Pina, un volver a mirar las imágenes, un volver a mirarla leyendo ahí lo impersonal de Pina.

\section{El documental como una (re)escritura de vida}

Es cierto que te llegan cosas, hechos del exterior que te influyen en la creación, pero es la vida, lo que sucede alrededor, lo que ejerce inevitablemente, una influencia sobre ti. Eso es: yo no diría que son precisamente los hechos artísticos los que me influyen. Yo trato de hablar de la vida. Pina Bausch. (Bentivoglio, 1991, p. 18).

¿Quién es Pina? Pregunta que pareciera generarse inmediatamente luego de ver los afiches publicitarios del largometraje en el cual ese nombre está escrito -en minúsculas ${ }^{2}$ - con unas imperantes letras rojas. Y debajo de él, la frase dance, dance, otherwise we are lost (baila, baila, de lo contrario estamos perdidos). Estas palabras coronan una imagen central de una bailarina, vestida de rojo, con el rostro cubierto por su pelo, a un salto (marcando así una distancia) del piso mojado. Una imagen compuesta por un fondo oscuro, en el que resaltan los rojos del título, del vestido, y la frase en letras celestinas que hacen juego con el brillo del agua. Esta imagen suspende a una bailarina -que luego de ver el film sabemos que integra la compañía de danza y que su movimiento es un fragmento de una de las obras que dirigió Pina-. La posición de la bailarina nos recuerda una imagen de un colibrí: los brazos en forma de " $v$ " con un breve quiebre de las muñecas, la cabeza inclinada, las rodillas juntas y recogidas producto del salto.

Este afiche del film convoca la figura de Pina -no sólo por el nombre-, sino también por la evocación de la danza, del movimiento. En una entrevista le preguntaron a Pina si estaba de acuerdo con describir o etiquetar su trabajo como teatro de la experiencia. Ella 
respondió con las siguientes palabras: "Fórmulas, etiquetas, definiciones. ¡Me han colgado tantas encima! Es la preocupación habitual de los críticos: quieren analizar, descomponer, encontrar a toda costa parentescos y clasificaciones. Pero yo no creo que esté dentro de ninguna categoría, ni quiero estarlo" (Bentivoglio, 1991, p. 18). Esta anécdota no sólo sirve para situar el trabajo de Pina, que no puede ser clasificado bajo ninguna etiqueta $-y$ cuando uno lo ve confirma esta afirmación-; sino también, para preguntarnos cómo Wenders trabaja con la producción de la coreógrafa. Este documental no intenta responder a la pregunta ¿quién es Pina?, sino más bien abrir ese mundo, introducirnos en el mundo de Pina que se compone desde la danza.

El proyecto de Wenders era realizar un film sobre la compañía de danza que dirigía Pina; pero no encontraba la manera de captar las particularidades del movimiento y la expresión de la danza en un formato $2 \mathrm{D}$, como dice en una entrevista: "nada más aburrido que el teatro filmado" (Cfr. Gainza, Página 12, 8 de octubre del 2011). La tecnología 3D³ es lo que le permite al director empezar a concretar este plan. Con el surgimiento de esta tecnología el director encuentra la posibilidad de producir un registro fílmico que se aproxime a las puestas en escena de la compañía de danza. Wenders utiliza esta nueva herramienta para una exploración, una búsqueda estética y no como un simple efecto óptico sensacionalista. ${ }^{4}$ En un primer momento la apuesta de Wenders y de Pina era filmar la gira que emprendería la compañía por Asia y por América, viaje que el director documentaría en 3D. Cuando Pina muere este plan deja de tener sentido para el director, pero luego de un tiempo decide retomarlo, tal como señala en una conferencia en Toronto:

Cancelé el proyecto porque no tenía sentido hacerlo sin ella. Pero después fueron los bailarines de su compañía los que me convencieron. Ya me había resignado a abandonar el proyecto. Había sido un sueño de 20 años y entendí a través de ellos que no podía renunciar definitivamente a él (Cfr. Stiletano, La Nación 4 de octubre del 2011).

A partir de este giro inesperado, el proyecto inicial es trasformado, ya no se trataría de realizar una película "sobre" Pina sino "para" Pina. Tal como afirma Wenders en la conferencia (Cfr. Stiletano, La Nación 4 de octubre del 2011), y se lee en la primera frase con la que comienza el film: For Pina. By all of us who made this film together (Para Pina. Para todos nosotros que hicimos esta película juntos). Este for, "para", a diferencia de un "sobre", que insinúa una fuerza que se ejerce desde un arriba, a veces con cierto dominio y superioridad, convoca un gesto de dar y de apertura. Este "para Pina" inmediatamente está acompañado por un "todos juntos", desplazando cualquier tipo de lectura que roce algún tipo de solipsismo, o con la intensión de construir un "yo" de Pina.

Wenders no decide contar una historia, la historia de un "yo", en forma lineal, cronológica, cerrada, de lo que fue la vida de Pina Bausch, sino más bien, abrirla. A partir de imágenesarchivos, partes de las coreografías, testimonios en voz en off y memorias bailadas por los integrantes de la compañía, teje un relato con el que surge el recuerdo de Pina o, más precisamente, algo de la vida de Pina. Si entendemos con Blümlinger (2007, p. 55) que "uno no recuerda, uno reescribe la memoria del mismo modo que se reescribe la historia", Pina, en tanto documental biográfico, puede ser pensado como un trabajo de (re)escritu- 
ra. Decimos (re)escritura para acentuar los dos modos de lectura que posibilita este juego. Un trabajo de escritura siempre exige un reescribir en la medida en que la escritura es un espacio múltiple en el cual se pierde todo tipo de "origen", de "fundamento"; se desplaza la figura del sujeto racional que dice "cogito ergo sum" ("pienso luego existo"). Podemos decir con Deleuze, el escribir siempre implica un escribir "con" (otro).

Volver a ciertos personajes (re)escribiendo una historia es un gesto, que encontramos en la producción del director, presente en Tokyo-Ga (1985) ${ }^{5}$-documental que tiene como apuesta reencontrar el Tokyo que había inspirado al director Yasujiro Ozu-. Wenders escribe entre el Tokyo que inspiraba a Ozzu y un Tokyo americanizado. Paseando entre ambos, intenta no sólo materializar el recuerdo de algunas de las imágenes que inspiró a Ozu, sino encontrar en la vorágine de la ciudad, de la vida moderna, algún resto de aquellas imágenes, algún resto de Ozu. A partir de entrevistas con Ryo -actor principal de casi todos los films de Ozu- y Atsuta -ayudante de cámara y luego cameraman-, se propone buscar la "esencia" del cine de Ozu, de él en tanto director. Tanto Tokyo-Ga como Pina pueden ser situadas en lo que Amado llama una "estética de lo límite":

Las tensiones entre vida y muerte, entre presente y pasado, entre el rastro y memoria, sólo pueden conjurarse en el marco de una estética límite o, más bien, de una ética de la imagen que, frente a la exhibición mediática banal, obscena y cotidiana de la violencia y de la muerte, opta por desplazarla fuera de la escena, a los bordes del relato, por lo tanto, sometiéndola al régimen de la supresión (Amado, 2009, p. 108). ${ }^{6}$

La (im)posibilidad de la narración biográfica yo tb hablo de las (im)posibilidades, en ambos documentales, se produce por una constante recuperación, ya sea de las obras, del relato de los que sí están, de las imágenes-archivos. Sin embargo, siempre se mantiene una constante tensión que nos recuerda que no es posible una recuperación "total". Rememorar, recordar siempre trae consigo el problema de la ausencia. Como un (re)escritor de "vidas", Wenders lleva fragmentos de éstas a su máxima expansión. Mientras que uno mira el documental Pina, se va produciendo una suerte de traición a este mismo nombre, tomando sentido la marca textual de la letra "p" minúscula con que comienza el nombre en el afiche. No sabemos muy bien quién es Pina en tanto sujeto de una vida personal, es decir, no se sabe nada sobre la cronología de su vida; sólo nos enteramos del año de su nacimiento y de su muerte al finalizar el largometraje. El documental traiciona la expectativa que genera el nombre propio que lleva como título, produciendo lo impersonal de Pina, aquello que se extiende más allá de su vida fáctica. Podemos decir que Pina-en tanto documental- nos recuerda lo siguiente: ésto no es sólo Pina o una imagen total de lo que es Pina, sino más bien una parte de su mundo, esa parte compuesta por la danza.

Entendiendo el largometraje Pina (2011) como una red, un tejido de imágenes que dispone el funcionamiento de diversos elementos, proponemos distinguir tres grandes sedimentaciones de este material fílmico. La primera, el teatro, espacio en el cual se desenvuelven cuatros obras Le Sacre du printems (1975), Café Müller (1978), Vollmond (2006) y Kontakthof (1978 - 2000 - 2008), elegidas por el director y la coreógrafa. La segunda, integrada por las participaciones que se filmaron en diversos lugares, dentro y fuera de Wuppertal: 
en la campiña de Bergisches Land, en laderas de montañas, en las calles y en los cruces de ruta, en instalaciones industriales y en el Wuppertal Suspension Railway. Estos diferentes espacios son elegidos por el director para grabar las "memorias" que bailan los integrantes de la compañía. Éstas son intercaladas en el documental con lo que describimos como una tercera sedimentación compuesta por los primeros planos de los bailarines que narran en voz en off sus recuerdos, su vivencia personal con la compañía, con Pina. El documental, como mencionamos anteriormente, también incluye imágenes-archivo de Pina. Las tres sedimentaciones son construidas a partir del predominio de algún elemento, de alguna fuerza sobre otras, lo que nos permite marcar rasgos particulares de cada una; tal como apuntamos más arriba, ellas conforman un tejido-fílmico.

\section{El bailarín como un espacio plegado...}

"No se vive en un espacio neutro y blanco; no se vive, no se muere, no se ama en el rectángulo de una hoja de papel” Michel Foucault (2010, p. 20).

El teatro, tradicionalmente, puede ser descripto como un espacio delimitado, acotado; un lugar en el que se realiza una acción ante espectadores. Pensándolo espacialmente, podríamos otorgarle una cantidad de metros cuadrados, de butacas o sillas, una capacidad, un domicilio. El film comienza con una imagen panorámica del edificio del Wuppertal Opera House, escenario habitual de la compañía. Luego de esta toma, se pasa al adentro del teatro, se muestra su escenario y en su fondo -tal cual una pantalla de cine- la inscripción que dice For Pina. By off us who made this film together, a la que le sigue una foto de Pina fumando.

En este escenario, luego del fallecimiento de la coreógrafa, se presentó parte de la producción que ella dirigió. La presentación incluía las obras que Pina y el director habían seleccionado para el primer proyecto. Wenders aprovechó esta oportunidad para grabar, con la presencia del público, Le Sacre du printems (1975) y Vollmond (2006). En el largometraje encontramos fragmentos de estas dos obras, como así también de Kontakthof (1978 2000 - 2008) -obra que, en una primera versión, es interpretada por bailarines; en una segunda, por personas de más de 65 años, completamente ajenas al mundo de la danza; $y$, en una última por adolescentes entre 14 y 18 años, también ajenos al mundo de la danzae imágenes-archivos de Café Müller (1978). Estas últimas ocupan un lugar privilegiado en el documental, ya que, recordemos que en esta obra no sólo Pina tiene el papel de coreógrafa, sino que también baila. En el film esta obra aparece, en un primer momento, proyectada desde lo que parece ser un reproductor super 8. Un bailarín da comienzo a la cinta y enciende un cigarrillo -gesto que evoca a Pina-, otros bailarines están sentados como espectadores mirando la pantalla. Principalmente se ven fragmentos de la obra en los que baila Pina y un segmento de una entrevista en la que cuenta la experiencia de bailar en Café Müller, acentuando en cómo un detalle (aquí, el bailar con los ojos cerrados) puede cambiar todo. Algunos fragmentos de la obra se van tejiendo con el relato de los bailarines que cuentan sus experiencias con la obra, con Pina. 
Podríamos decir que al entrar al teatro se da comienzo al film. Las primeras imágenes nos posicionan en el rol de un espectador de teatro. Con una toma general del escenario, como si estuviéramos sentados en alguna de las filas del final, se nos introduce al mundo de la compañía. Vemos el escenario, hileras de butacas por delante de nuestra mirada con sombras de cabezas de otros espectadores ficticios. En otras escenas, como las que describimos de Café Müller, los bailarines también son espectadores. Entrar al teatro, experiencia en la que nos sumerge el film, implica al mismo tiempo tomar contacto con la danza, con su protagonista el bailarín.

Creemos que la mirada que se construye sobre el espacio de la danza, desde el film, no es reducido al ámbito convencional del teatro. Wenders, en sintonía con el trabajo de la compañía, nos traslada a otros espacios, a la ciudad, a la campiña, al tren, etc. Para Pina Bausch "los elementos son importantes: arena, tierra, agua, incluso rocas aparecen en el escenario", tal como cuenta un bailarín. En los diferentes fragmentos de las obras que vemos, algunos de estos elementos están presentes, como así también objetos: mesas, sillas, palos, sogas, etc.; pero ninguno de éstos se utiliza con fines decorativos. En las escenografías no hay nada inútil, todo puede ser usado, todo tiene un papel que compone y transforma el escenario. En el largometraje, el espacio de la danza no queda acotado al escenario del teatro, su afuera se presenta como un viable escenario, produciéndose un "entre" diferentes espacios.

Las puestas en escena de la compañía que están montadas en el documental trascurren tanto en el teatro como en su afuera. En este sentido, decimos que se "abre" un espacio, o dicho con otras palabras, se produce un "entre" justamente entre ambos espacios que no es ni el adentro, ni el afuera. Esta apertura se produce desde el actor de la danza: el bailarín es quien habita y compone estos diferentes espacios. Pina decía, "Mi repetición no es más que la repetición de modo siempre diferente, de un mismo tema: el tema es el amor, es como todo nosotros, siempre queremos ser amados" (Bentivoglio, 1991, p.20). Y, continuamos estas palabras con nuestro epígrafe "[n]o se vive en un espacio neutro y blanco; no se vive, no se muere, no se ama en el rectángulo de una hoja de papel” (Foucault, 2010: 10). Si bien Foucault pronuncia estas palabras en el contexto de su conferencia radiofónica "Las heterotopías", las trasladamos para pensar el espacio del teatro en tanto no funciona -ni en la compañía, ni en el film- como el rectángulo de la hoja de papel, un rectángulo limitado, cerrado. Los bailarines atraviesan los espacios por los que cuales transcurre la vida misma: trenes, calles, parques, fábricas, edificios vacíos, devienen posibles escenarios. Desbordan el rectángulo del teatro, caminando, corriendo, saltando, arrastrándose, deteniéndose, abrazándose, besándose, chocándose. Todo tipo de sensación, de sentimiento, es movimiento, es danza; en la quietud más absoluta hay un cuerpo que respira, un corazón late, una piel que suda. Los bailarines se sitúan en esa frontera en la que se construyen nuevas relaciones entre el cuerpo, el movimiento y el espacio.

El bailarín, la bailarina, los bailarines, las bailarinas, todos ellos, juntos, separados, de a uno, de a dos, de a tres o más, se visten de anómalos, habitando en la frontera del adentro y de su afuera. Atraviesan el espacio, al mismo tiempo que lo van componiendo y se componen. Un dúo baila a la orilla de la calle, de fondo está la ciudad, los autos y las motos siguen su tránsito, pero lo que vemos a las orillas, de fondo, no es un simple paisaje, es un escenario. Los bailarines no son unos extraños en ese espacio, lo habitan, lo componen, lo transforman. 
Podríamos pensar este espacio "otro" con aquello que Foucault denomina como heterotopías: "espacios absolutamente diferentes"; son esos lugares reales que están por fuera de todos los espacios. A diferencias de las utopías, que "son los emplazamientos que mantienen con el espacio real de la sociedad una relación general de analogía directa o invertida" (Foucault, 2010, p. 69). El "entre" que se produce en el documental traza un surco, una grieta que posibilita el surgimiento de un espacio nuevo, que puede ser pensado como un contraespacio radicalmente diferente. ${ }^{7} \mathrm{Y}$ nos preguntamos, ¿es posible, en este espacio heterotópico, pensar el papel del bailarín como un cuerpo utópico? Se nombra al cuerpo como utópico porque "es el punto cero del mundo, allí donde los caminos y los espacios vienen a cruzarse el cuerpo no está en ninguna parte" (Foucault, 2010, p. 16). El cuerpo utópico es entendido como un espacio de posibilidad, y de ahí como un actor principal. Desde nuestra lectura, bailar la memoria, el recuerdo, que tiene cada uno de los bailarines de Pina, o, más precisamente, bailar a Pina, es posible, a partir del desplazamiento de una noción de cuerpo limitado, que se construye en relación con un determinado espacio, cuerpo territorializado. En el documental, el "entre" del adentro y del afuera permite la emergencia del cuerpo utópico, tal como es entendido por Foucault. Los cuerpos como posibilidad y no como un límite o una barrera.

Pina no les daba a los bailarines consignas, direcciones de trabajo, siempre apelaba a la exploración de sus deseos, anhelos, miedos. Sus pocas intervenciones parecen palabras oraculares, encriptadas, que no apelan a un único sentido: "baila por amor", "sólo tienes que enloquecer un poco", "sigue buscando", nos enteramos a partir de la voz en off de los bailarines. Estas exploraciones producen en los bailarines diversas reflexiones y sensaciones: "nos enseñó a defender lo que hacemos con gestos", "Pina era una exploradora radical que vio en las profundidades de nuestras almas". Leemos en una entrevista a Pina que si algo tiene en común con uno de sus maestro (Kurt Jooss) es su modo de trabajar, él le enseñó que la característica principal para trabajar era tener en cuenta la personalidad de individual de los bailarines. Reflexionando sobre esto, Pina comenta:

Esa es la cosa más importante que creo tener en común con Jooss. Ese querer trabajar siempre sobre lo subjetivo (...) Cuando realizo un espectáculo puedo tener ideas, puedo inventar preguntas con las que estimular a mis bailarines, pero deben ser siempre ellos (y cada uno de su manera distinta, partiendo de ellos mismos) los que me proporcionen el material para el espectáculo. Eso es lo que tengo en común con Jooss, este querer trabajar sin prescindir nunca de las personas con las que estoy trabajando (Bentivoglio, 1991, p. 18).

Un bailarín comenta en el film "siempre te sentís más que humano trabajando con Pina", una bailarina dice "con Pina se puede ser anciano y niño al mismo tiempo". A lo que podemos agregar a partir de algunas imágenes que conforman el documental, se puede ser una máquina, un robot-sonidos a los que nos remite una bailarina que sube bailando a un tren-, se puede ser un animal -bailar con uno o sólo tener sus orejas-; se puede ser lo que se quiera ser, por eso ser sólo humano es poco. Dirá Foucault (1968, p. 9) "reconforta y 
tranquiliza el pensar que el hombre es sólo una invención reciente, una figura que no tiene ni dos siglos, un simple pliegue en nuestro saber y que desaparecerá en cuanto éste encuentre una forma nueva". El trabajo que realiza Pina implica un trabajo desde la propia subjetividad -tal como dice en la entrevista- desde un sí-mismo que siempre es diferente. Desde su propio cuerpo, que sabemos que "de hecho, está siempre en otra parte, está ligado a todas otras partes del mundo" (Foucault, 2010, p. 16), una bailarina baila a Pina, pensándola como "algo ligera", el pensamiento se une al movimiento. Moverse-bailar implica al mismo tiempo pensar, producir flujos de pensamientos, subjetividades móviles. El documental, a partir de un baile-pensamiento, (re)escribe una posible Pina. Por eso, todas las imágenes que conforman el documental no pretenden ilustrar a Pina, cada una se produce desde su propia diferencia. Y retomamos una pregunta foucaultiana: “ $¿$ acaso el cuerpo del bailarín no es justamente un cuerpo dilatado según todo un espacio que le es interior y exterior a la vez?" (Foucault, 2010, p. 15). Un trabajo sobre sí-mismo, tal como propone la compañía de danza que dirigía Pina, implica un pliegue sobre un pliegue, un "bailar, bailar, para no perdernos".

\section{Notas}

1. Cursivas en el original.

2. Hay una variante de este afiche en el que todas las letras del nombre Pina están escritas en mayúscula, lo que nos interesa recalcar como marca textual es que el nombre propio no está escrito con mayúscula.

3. Actualmente hay un debate, que no profundizaremos aquí pero que no podemos dejar de mencionar, en relación con el nuevo dispositivo 3D. Algunas de las preguntas que han emergido a partir de esta tecnología son por ejemplo: qué se puede esperar en término de innovación estética o escenográfica, posibilidades de tacto visual, de subdesglose de los planos de profundidad, de escalonamientos, de duración de los planos, etc. Claude Baiblé, cineasta y teórico francés, considera que esta etapa de desarrollo audiovisual debe ser llamada con más precisión 2D y 1/2, ya que sólo la realidad es en 3D y que esta denominación se circunscribe más una pauta de mercado, de publicidad (Cfr. Rioseco, 2012).

4. Otro director que se ha servido de la tecnología 3D es Werner Herzog en el documental La cueva de los sueños olvidados (2010). Podríamos decir que Herzog usa esta herramienta para expresar el volumen de las pinturas de la caverna y Wenders para expresar el movimiento de la danza.

5. Otros documentales que podríamos citar como reescrituras de "vidas" son Notas sobre vestimentas y ciudades (1989), Buena Vista Social Club (1999).

6. Es importante aclarar que estas reflexiones por parte de la autora, se producen dentro de un marco delimitado por el cine argentino (1980-2007). Principalmente los documentales dedicados a la postdictadura (Arqueologías de la ausencia (2000-2001) de Lucila Quieto, Los rubios (2003), de Albertina Carri, M (2007), de Nicolás Prividera, entre otros). Pero consideramos que este planteo se circunscribe un contexto tanto teórico, filosófico como 
político que podríamos bordear a partir de la imposibilidad de la "representación", tiene como efecto el desencanto y la problematización de conceptos como "verdad", "historia", "memoria" etc.

7. Escribir una historia de los espacio, en el pensamiento foucaultiano, es al mismo tiempo escribir una historia de los poderes (Cfr. Defert en Foucault, 2010).

\section{Referencias Bibliográficas}

Amado, A. (2009). La imagen justa. Cine argentino y política (1980-2007). Buenos Aires: Ed. Colihue.

Bentivoglio, L. (1991). Dialogando con Pina Bausch en El Público, no 87-Noviembre/Diciembre 1991, Madrid: Centro de Documentación Teatral-INAEM.

Blümlinger, C. (2007). Leer entre las imágenes en La forma que piensa. Tentativas en torno al cine-ensayo. Navarra: Fondo de publicación del Gobierno de Navarra, pp. 50-63.

Defert, D. (2010). "Heterotopía": Tribulaciones de un concepto entre Venecia, Berlín y los Ángeles en El cuerpo utópico. Las heterotopías. Buenos Aires: Ed. Nueva Visión, pp. 33-62. Deleuze, G. (2009). Crítica y clínica. Barcelona: Anagrama.

Gainza, M. (2011, 08 de octubre). Bailando en la dimensión desconocida en Página 12, Radar. Recuperado de http://www.pagina12.com.ar/diario/suplementos/radar/9-73742011-10-10.html

Foucault, M. (2010). El cuerpo utópico. Las heterotopías. Buenos Aires: Ed. Nueva Visión. (1988) "El sujeto y el poder" en Revista Mexicana de Sociología, Vol. 50, N 3, julio-setiembre, pp. 3-30.

(1968). Las palabras y las cosas. Una arqueología de las ciencias humanas. Buenos Aires: Siglo XXI.

Nietzsche, F. (2007). Más allá del bien y del mal. Buenos Aires: Alianza.

Rioseco, C. (2012). El cine 3D. Su impresión, el desengaño y la excepción en Revista La Fuga. Recuperado de: http://www.lafuga.cl/

Stiletano, M. (30 de febrero de 2011). Pina: la danza según Wim Wenders. La Nacion. Recuperado de: http://www.lanacion.com.ar/1411529-pina

Ulm, H. (2011). Cuestión de imágenes: charlas de artes y filosofía, Salta. Ediciones de la Galería el Fedro.

Weinrichter, A. (2007). Un concepto fugitivo. Notas sobre el film-ensayo en La forma que piensa. Tentativas en torno al cine-ensayo. Navarra: Fondo de publicación del Gobierno de Navarra, pp. 18-48.

\section{Filmografía}

Wenders, W. (2011). Pina. Alemania-Francia-Inglaterra. 
Summary: This article presents the analyse of the film Pina (2011) by Wim Wenders. The documentary is about the history of the dancer Pina Bausch, more precisely, the story of Pina as director and choreographer of the Tanztheater Wuppertal. Filmed in urban and natural scenery of the German -Wuppertal city, home of the company, and with the help of 3D technology, the film is composed of fragments of works, memoirs, and pictures.

As a starting point the article approaches the notion of film-esay and its link to the biographical documentary. It also describes some aspects of the film that we believe could match with this non-gender- called film-esay. We work with the images of the film not as representations of reality, but as producers ones; images not only produce the world but they produce ourselves. In this sense, the "we" that accompanies the verb "produce" challenges us, as subjectivity. And we wonder what would happen with Pina without these images that make possibe to think about her?. Is it possible to think about her as something independent of the images production? We believe that questionning about the biographical implies to pose a quiestion about subjectivity and their modes of production. From these problems, we approach the in-and-out theater space to think the dance theater space and the dancer's body as an actor and producer.

Key words: cinema - film essay - Pina - Wenders.

Resumo: O artigo propõe uma leitura do filme Pina (2011) de Wim Wenders. Documental que trata sobre a história da bailarina Pina Bausch, mais precisamente, a história de Pina como diretora e coreógrafa de Tanztheater Wuppertal. Filmado em cenários urbanos e naturais da cidade alemão -Wuppertal, casa da companhia- e com ajuda da tecnologia 3D, o filme se compõe de fragmentos de obras, memórias, bailadas pelos integrantes da companhia e imagens arquivo.

O ponto de partida se expõe a noção de ensaio-fílmico e sua relação com o documental biográfico. Descrevem-se alguns dos aspectos do filme não como representações de uma realidade senão como produtoras; as imagens não somente produzem o mundo, senão que nos produzem. Neste sentido, o nos que acompanha o verbo produzir nos interpela, em tanto subjetividade. E a pergunta surge: que seria de Pina sem essas imagens que possibilitam pensa-la? Acreditamos que abrir uma pergunta sobre o biográfico implica perguntar-se sobre a subjetividade e seus modos de produção. A partir destes problemas, a reflexão será sobre o espaço do teatro -seu adentro e seu fora- para poder pensar um espaço outro da dança, o corpo do bailarino, como ator-produtor.

Palavras chave: cinema - ensaio fílmico - Pina - Wenders. 